\title{
Research of Hydrodynamic Flame Stabilizer with Cross Fuel Feed Characteristics
}

\author{
Michail Abdulin ${ }^{1}$, Alexander Siryi ${ }^{2}$, \\ 1-2 National Technical University of Ukraine "Kyiv Polytechnic Institute"
}

\begin{abstract}
The article presents the results of numerical researches of hydrodynamics, mixing processes and stabilization characteristics of jet and niche system of gas fuel combustion. On the basis of this system has been created the universal technology allowing more effectively use natural gas in the industry and power engineering. This article shows the results of the steam boiler DE-25 modernization which has been carried out on the basis of jet and niche technology. Study of the geometrical parameters impact on the furnace burner work plays an important role in the design of the increased heat capacity furnace burner.
\end{abstract}

Keywords - jet and niche system, stabilization, mixing process, range.

\section{INTRODUCTION}

Organic fuel combustion is one of the main power generation methods required for power assets needs. Mankind utilizes million tons of fuel per annual in imputed value. The most widespread fuel type in modern power engineering is natural gas, the use of which has certain peculiarities of work process organization and requires considering its chemicophysical characteristics during combustion at industrial plants.

1. Temperature - the temperature of natural gas ignition is high enough of $650{ }^{\circ} \mathrm{C}-750{ }^{\circ} \mathrm{C}$.

2. Velocity - in technological processes of boilers, furnace, driers, etc. the combustible flows are injected into fuel volume with the velocity of ten, even hundreds meters per second, that is ten times higher than normal flame spreading velocity, the value of which depends on the fuel type and reagent temperature does not reach more than $1 \mathrm{~m} / \mathrm{s}$.

3. Consentration - to enable steady combustion the combustible mixture have to comprise $5 \%-15 \%$ of natural gas with the total reaction components amount.

4. Thermal - the amount of heat released in the reaction process have to ecxeed the amount of removed heat.

To prevent flameout it is necessary to establish requisite conditions for stabilization, i.e. continuous combustion initiation in the fixed furnace areas. Research analysis of combustion in a stream allows selecting several ways for the flame front stabilization:

- stabilization as a result of power supply from the external source of continuous operation;
- stabilization as a result of power supply from the combustion area.

In the first case, this is achieved by the so-called emergency furnace burner, in the second - the power is generated from a heated body or reverse-flow area of highly heat combustion products, which occurs with the flow swirl; system for bluff bodies of various geometric shapes, or the hydrodynamic flow interaction, etc. [1].

The efficiency of flame stabilization process can be evaluated for a range of criteria related to operation, stabilizer performance characteristics and the degree of its impact on the operation process of fire engineering objects:

1) The range of stabilization by the flow rate and excess air coefficient.

2) Reliability of the combustion chamber starting with this type of stabilizer.

3) The source of the stabilization device.

4) Hydraulic resistance of the stabilization device.

5) The impact of stabilizer on the combustion efficiency, extension of the combustion area.

6) The simplicity and low price of the construction.

7) Construction maintainability, providing flame stabilization [2].

\section{RESEARCH TASKS}

The main task of the research: study of the flow dynamics in the near wake of the fuel jet system in the oxidant crossflow; evaluation of the jet and niche system stabilization qualities on the flat gas distributing pylons depending on its geometrical characteristics (Fig. 2) and the development of recommendations for the design of jet and niche furnace burners.

Study of the geometrical parameters impact on the furnace burner work plays an important role in the design of the increased heat capacity furnace burner, their development and installation on the fire engineering objects in existing burner arch during their modernization is becoming increasingly important. While modernizing the fire engineering objects it is important to preserve the existing structure of units without dismantling the cooling rings and extension of the seats under the furnace burner. Existing dimension-types jet and niche furnace burner do not always satisfy (due to the limited air flow section) required parameters in power see Figure 1. 


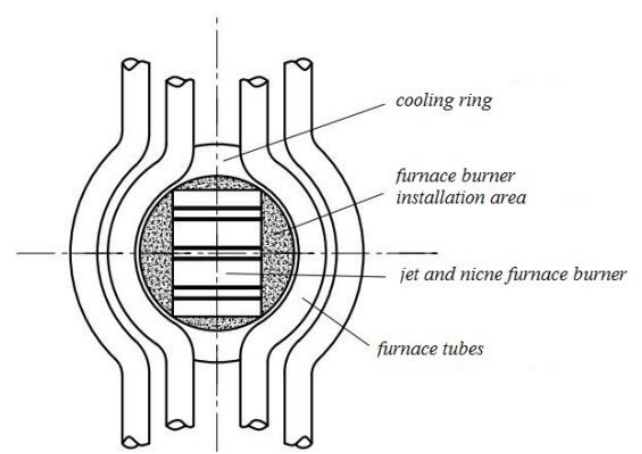

a)

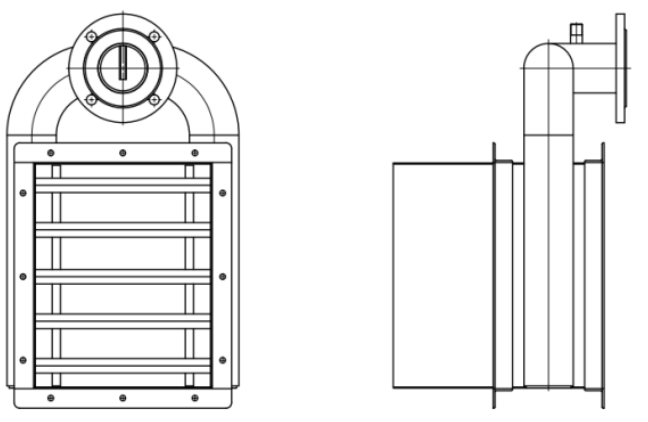

b)

Fig. 1. Boiler Unit Structure (before modernization vortex furnace burner with swirl flow were operated) - a; jet and niche furnace burner -45 , equipped with flame throw-over jumpers $-b$.

This paper continues the study of stabilization features of the flat jet and niche pylon system with perpendicular jets entering the gaseous fuel by varying the geometrical and operational parameters of devices. On the basis of these pylons the fuel combustion jet and niche technology is working and developing [[3], [4], [5], [6]]. Basic operating and geometrical parameters of the jet and niche system are presented in Fig. 2.

Figure 2 shows a jet and niche system consisting of a bluff body in the form of a flat pylon comprising rectangular cavity on the top and bottom flat surface and on its end face simultaneously acting as a fuel-dispensing header.

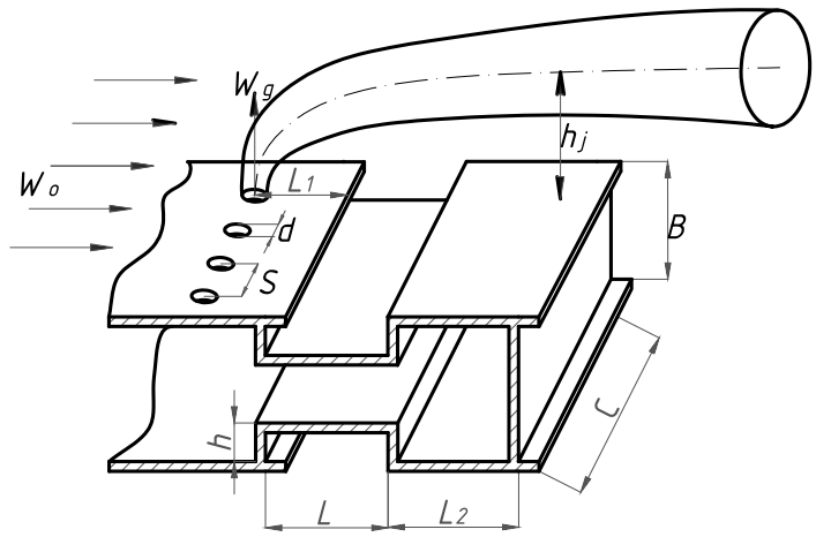

Fig. 2. Jet and niche system, located on the flat fuel-dispensing header, $h_{j}$ jets depths of penetration in oxidizer flow, (other conventional signs shown under the fig. 3).
III. PHYSICAL MODEL OF FUEL AND OXIDANT DISCHARGE IN THE JET AND NICHE SYSTEM

To define research problems let consider physical model of fuel and oxidizer flow in the jet and niche system in more details [3] (Fig. 3).

a)

b)

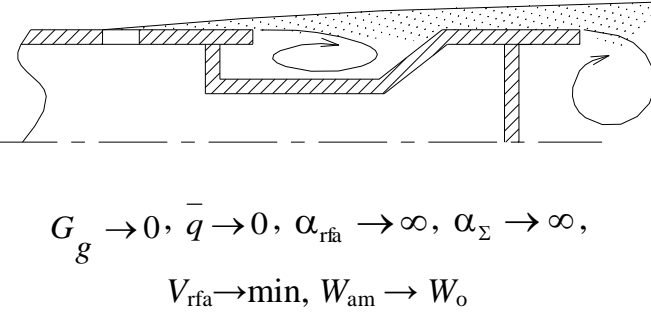

$$
G_{g} \rightarrow G_{g}^{\text {ignition }}, O<\bar{q}<q_{\mathrm{cr}}^{\mathrm{I}}, \infty<\alpha_{\mathrm{rfa}}<1
$$

c)

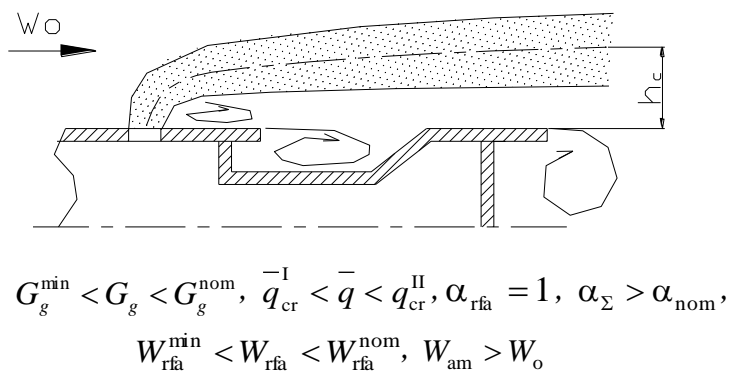

d)

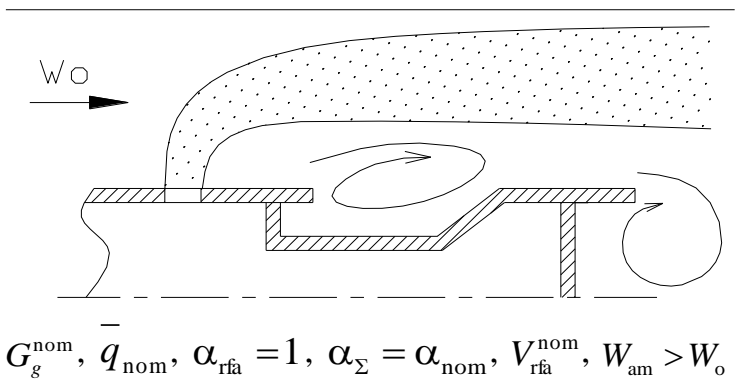


e)

f)
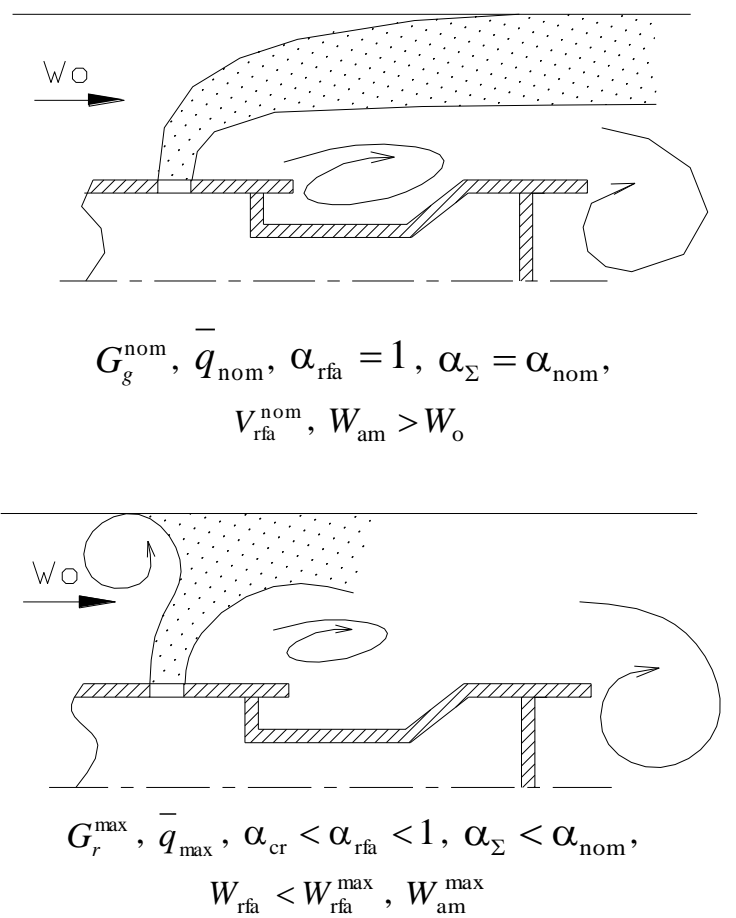

Fig. 3. Physical model of hydrodynamics and mixing process in jet and niche module where: $G_{g}$ - fuel consumption, $\rho_{g}, \rho_{o}$ - fuel and air density respectively; $W_{g}, W_{o}-$ fuel and air velocity, $q=\frac{\rho_{g} W_{g}^{2}}{\rho_{o} W_{o}^{2}}-$ hydrodynamic option; $\alpha_{\mathrm{rfa}}-$ excess air ratio in a reverse-flow area, $W_{\mathrm{am}}^{\max }-$ oxidant velocity, which flows round fuel jet.

The most favorable mode of the system operation is the variant when the $\alpha_{\mathrm{rfa}}=1$ is provided (Fig. $3 \mathrm{c}, \mathrm{d}, \mathrm{e}$ ). Modes at the minimum and maximum gas flow rate are critical and define the boundaries of the lean and rich flameout, thereby determining conditions for the stable operation of the device without flameout and flashback. In this case, the hydrodynamic parameter $q$ is a universal criterion for evaluating the possibility of stable system operation. Researches show that jet and niche system provides selfsimilarity of mixing process in a wide range of loads, and thus the hydrodynamic parameter $q$ [7]. Nominal mode of jet and niche furnace burners correspond to $10-12$, for $q<2$, the Coanda effect occurs, that is when the jet outflows it adheres to the wall $\left(q_{\mathrm{cr}}^{\mathrm{I}}\right)$. The maximum value of $q$ depends on the value of channel flow section shading and can reach values of $40\left(q_{\mathrm{cr}}^{\mathrm{II}}\right)$.

\section{RESULTS OF NUMERICAL EXPERIMENTS}

One of the main research methods is numerical modeling of hydrodynamic and mixing processes with the use of open integrated platform. At the same time it has been solving the system of differential equations, which in the Cartesian coordinate system can be represented as follows [6]:

$$
\begin{gathered}
\frac{\partial \rho}{\partial t}+\frac{\partial\left(\rho U_{j}\right)}{\partial x_{j}}=0, \quad j=1,2,3 \\
\frac{\partial}{\partial t}\left(\rho U_{i}\right)+\frac{\partial\left(\rho U_{j} U_{i}\right)}{\partial x_{j}}=-\frac{\partial P}{\partial x_{i}}+\frac{\partial\left(\tau_{i j}\right)}{\partial x_{j}}, i=1,2,3 ;
\end{gathered}
$$

$$
\begin{gathered}
\frac{\partial \rho_{K}}{\partial t}+\frac{\partial\left(\rho_{K} U_{j}\right)}{\partial x_{j}}=\frac{\partial}{\partial x_{j}}\left(\frac{v}{S c_{K}}+\frac{v_{T}}{S c_{T}}\right) \frac{\partial \rho_{K}}{\partial x_{j}}+R_{K} \\
K=1,2,3 \ldots K-1 . \\
\tau_{i j}=\mu\left(\frac{\partial U_{i}}{\partial x_{j}}+\frac{\partial U_{j}}{\partial x_{i}}+\frac{2}{3} \delta_{i j} \frac{\partial U_{i}}{\partial x_{j}}\right) \backslash
\end{gathered}
$$

The computational domain is shown in Fig. 4 (shaded), its geometric characteristics are as follows: width and length of the stabilizer $B_{\mathrm{st}}=36 \cdot 10^{-3} \mathrm{~m} ; L_{\mathrm{st}}=1 \cdot 10^{-2} \mathrm{~m}$, the channel length $L_{\mathrm{ch}}=0.6 \mathrm{~m}$ location of stabilizers $H$ is $0.12 \mathrm{~m}$ and $0.06 \mathrm{~m}$, which corresponds respectively to the values of $k_{\mathrm{f}}=0.3$ and $0.6\left(K_{\mathrm{f}}=B_{\mathrm{st}} / B_{\mathrm{h}}\right)$; air rate at the channel inlet is $U_{\mathrm{o}}=10 \mathrm{~m} / \mathrm{s}$, air temperature $t_{\mathrm{o}}=25^{\circ} \mathrm{C} ; U_{\mathrm{g}}$ varies depending on the diameter of the gas distributing inlet for $\alpha \approx 1.05 ; t_{\mathrm{g}}=25^{\circ} \mathrm{C}$. As the velocity scale is the average velocity in interstabilization channel $\bar{U}_{\text {ST }}$, as the length scale is stabilizer width $B_{\text {st }}$.

Only a front niche cavity is presented in the considered geometry. This design of stabilizers is adopted to simplify the numerical calculations (see Fig. 4).

The boundary conditions for the equation system 1-3 are set as follows: in the inlet areas are set constant values (concentration, temperature, velocity, etc.) and in the output areas - are set soft boundary conditions, on the solid boundaries are set adhesion conditions for the velocities and the equity of first derivatives is zero, normally to these surfaces from the mixture component concentration.

While stabilizing the combustion process of bluff body it is essential to evaluate the reverse-flow area size and the residence time of the mixture elementary volume in this area [8], [9]. In this system the overall flow pattern is determined by the hydrodynamic interaction in interstabilization area [10]. Then the gas cross flow suddenly enters the expanding channel, forming stable vortex structures for each gas distributing pylon. An important task in this situation is to determine the impact of the jet diameter, their flow velocity and the pylons location in the overall reverse-flow area system.

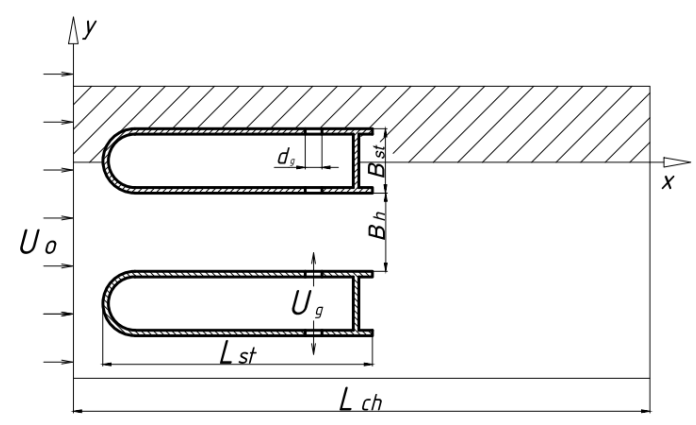

Fig. 4. Computational domain configuration.

To make a right choice of rational parameters for the jet and niche furnace burner design it is necessary to determine the impact effects of the gas feed inlet diameter on the characteristics of the residence time of mixture elementary volume and mixing process characteristics. The following contains the numerical studies results of the hydrodynamics processes in the jet and niche system for the $G_{g}=$ const in 
changing the diameter of the gas supply inlets and location of flame pylons. Fig. 5 shows the values of the axial velocity component along the channel length in the wake of a stabilizer $(a, c)$ and in the jet interstabilization core $(b, d)$ in the cross section through the center of the gas feed inlet.

The results of studies have shown that increasing the value of $\mathrm{K}_{\mathrm{f}}$ leads to the increase of the reverse-flow area length and reverse-flow area velocity values. Apparently the gas jet feed also has some effect on the performance of the circulation zone.

Thus, the input gas jets and especially the inlet diameter increase also increases the size and flow rate reverse currents in the area of stabilization for $K_{\mathrm{f}}=0.3$ (Fig. 5). With more cluttered effect of air section the influence of diameter change on the reverse-flow area velocity and size is leveled. Apparantely, it is explained by considerable flow acceleration. When $K_{\mathrm{f}}=0.3$ the interstabilization jet is less squeezed by walls of cracks in comparison with $K_{\mathrm{f}}=0.6$ and therefore expiration mixture is characterized by lower velocity step in the jet core and the more uniform field of axial velocity in the flow core. Furthermore, there is some interstabilization jet velocity increase at fuel inlet in a cross-flow oxidant. For an assessment of jet and niche system stabilization qualities a lot of calculations were carried out. Average mixing particle residence time in reverse-flow area can be used as the main criterion:

$$
\tau_{R}=\frac{\Omega_{3}}{S_{3} \bar{W}_{\text {out }}}
$$

where $\Omega_{3}, S_{3}-$ volume and surface area in a reverse-flow zone; $\bar{W}_{\text {out }}$ - average gas out velocity through the surface of this area. These sizes were defined as a result of data processing of computational experiments.

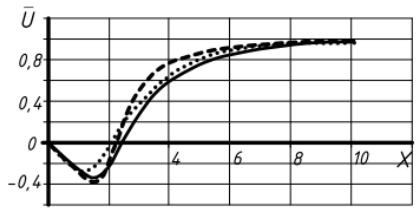

a)

c)

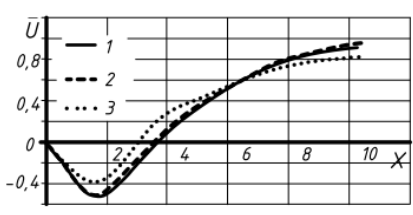

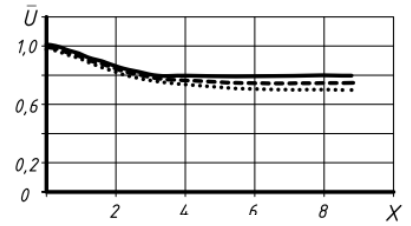

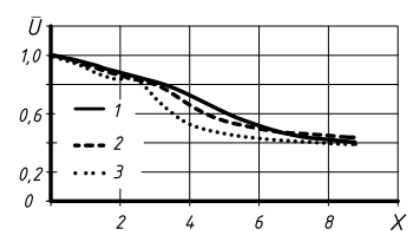

d)
Fig. 5. Axial velocity component change on an axis track benınd the stabilizer (a,c) and on the axis of interstabilization jet (b, d) for $G_{g}=$ const, $\alpha=1.05$; $1-\mathrm{d}=10 \mathrm{~mm}, 2-\mathrm{d}=5 \mathrm{~mm}, 3-$ air flow, $K_{\mathrm{f}}=0.3-(\mathrm{a}, \mathrm{b}), K_{\mathrm{f}}=0.6-(\mathrm{c}, \mathrm{d})$ air velocity $W_{\mathrm{o}}$ for $K_{\mathrm{f}}=0.3$ and 0.6 equaled $10 \mathrm{~m} / \mathrm{s}$ and $20 \mathrm{~m} / \mathrm{s}$ respectively, thus, fuel velocity varied $W_{g}$ within $62 \mathrm{~m} / \mathrm{s}-32 \mathrm{~m} / \mathrm{s}$.

Stabilization characteristics were estimated in a case of gas jet feed and without it. The results of calculations for an air flow stabilizers are given below:

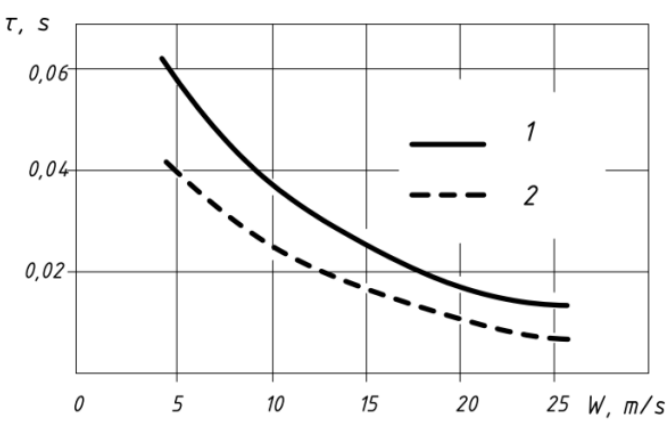

Fig. 6. The residence time of elementary air volume in a reverse-flow area for flat pylons at: stabilizer width $B_{\mathrm{st}}=36$; stabilizers arrangement pitch $H=120$ and $60 \mathrm{~mm}$ at $K_{\mathrm{f}} 0.3,0.45,0.6$ respectively, depending on the air flow rate $\left(1-K_{\mathrm{f}}=0.3 ; 2-K_{\mathrm{f}}=0.6\right)$.

Raushenbah has obtained the dependence of time spent by the mixture particle for angled stabilizers:

$$
\tau_{R}=k \frac{h}{\omega} \text {, sec }
$$

where: $h$ - stabilizer characteristic size - its height;

$\omega$ - free-stream velocity, $\mathrm{m} / \mathrm{s}$;

$k$-proportionality factor, depending on the stabilizer geometry [1].

For example, the stabilizers for the $\mathrm{V}$-shaped angle $\beta=30^{\circ}$, at cold blowdowns and when burning $\mathrm{k}$ is respectively equal 37 and 104. Comparison of the obtained calculated data with the values $\tau$ received according to formula (5) gives satisfactory compliance of the results.

In fig. 5 the time $\tau_{\Pi i}$ decreases with increasing $W_{\mathrm{o}}$ and $K_{\mathrm{f}}$ in all considered range of values.

\section{TABLE I}

The Residence of THE MiXTure Elementary Volume in a Flame STABILIZATION ZONE IN JET AND NICHE SYSTEM

\begin{tabular}{|c|c|c|c|c|c|c|c|c|}
\hline$K_{\text {f }}$ & \multicolumn{5}{|c|}{0.3} & \multicolumn{5}{c|}{0.6} \\
\hline $\boldsymbol{D}, \mathbf{m m}$ & - & $\mathbf{5}$ & $\mathbf{7 . 5}$ & $\mathbf{1 0}$ & - & $\mathbf{5}$ & $\mathbf{7 . 5}$ & $\mathbf{1 0}$ \\
\hline $\boldsymbol{L}_{\mathrm{rfa}}$ & 2.07 & 2.05 & 1.6 & 2.22 & 2.71 & 2.97 & 3.43 & 3.22 \\
\hline $\boldsymbol{\tau}_{R i} \mathbf{1 0}^{-2} \mathbf{S}$ & 3.8 & 6.0 & 9.34 & 9.86 & 1.2 & 3.3 & 7.4 & 6.9 \\
\hline
\end{tabular}

Data on stabilization characteristics of reverse-flow area are provided for the case of jet supply. Altogether jet fuel slightly increases fuel residence time in the reverse-flow area irrespective of the blockage size of a flow flame pylones. Especially this effect is shown in the case of implementation of gas jets with a diameter of $7.5 \mathrm{~mm}$ and more. Thus: $\tau_{R i}$ in the case of fuel jet input with a diameter of $5 \mathrm{~mm}$ is 1.5 times increased, and in the case of $\mathrm{K}_{\mathrm{f}}$ increase to 0.6 size and diameter to $10 \mathrm{~mm}$ - almost 6 times (in comparison with an air flow of pylons), that is explained, apparently, by increase in influence of shielding airflow fuel jets. This fact is confirmed by increasing in value of static pressure in the reverse-flow area (calculation results show an increase in rarefaction when in the case of the gas jets input on 5-10 Pas in case of $K_{\mathrm{f}}=0.3$, and on $25-30$ Pas in case of $K_{\mathrm{f}}=0.6$ ). 
Numerical modeling of mixing processes in stabilization area for jet niche stabilizer stalling edge was executed for obtaining recommendations about optimization of the furnace burner parameters. Results of numerical modeling of isothermal mixing processes of fuel flows and oxidizer are given below. Isolines of the excess air ratio are presented in the wake of a single flame stabilizer (see Fig. 7, Fig. 8).

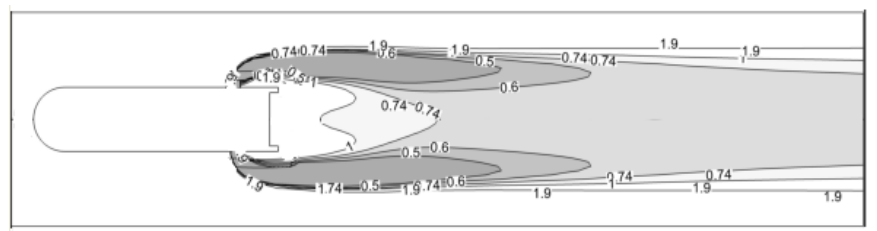

a)

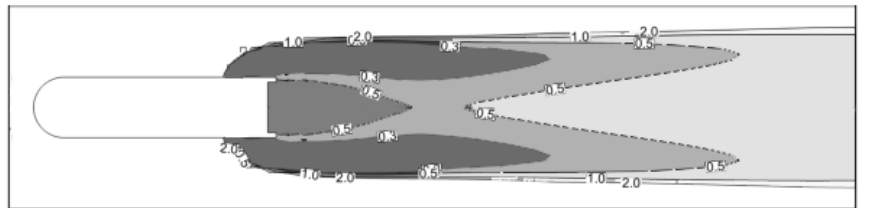

b)

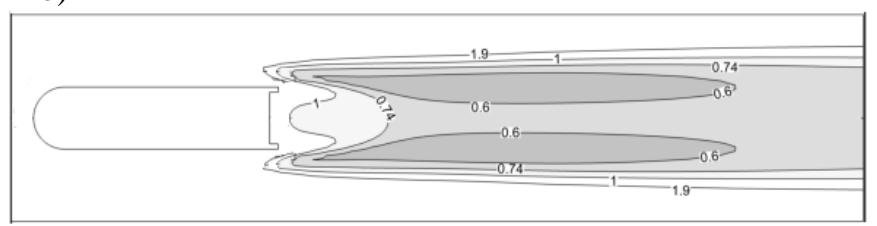

c)

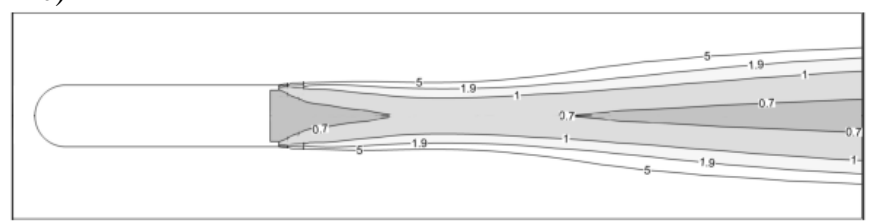

d)

Fig. 7. Contours of excess air ratio in the wake of a flat flame pylon when entering perpendicular to the gas jets in the entraining flow oxidizer at $K_{\mathrm{f}}=0.3$ : the diameter of the gas supply inlet $d=5 \mathrm{~mm}-\mathrm{a}, \mathrm{c} ; \mathrm{d}=10 \mathrm{~mm}-\mathrm{b}$, d, in a plane passing gas supply inlet through the middle $-\mathrm{a}, \mathrm{b}$; in the plane passing between the gas supply inlet $-\mathrm{c}$, d.

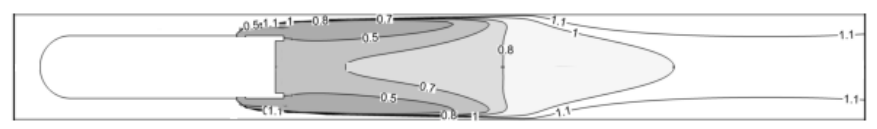

a)

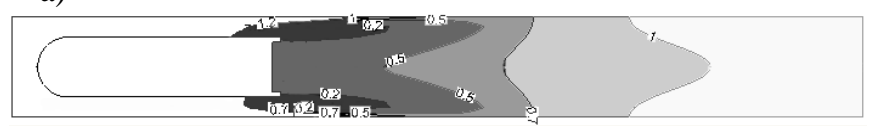

b)

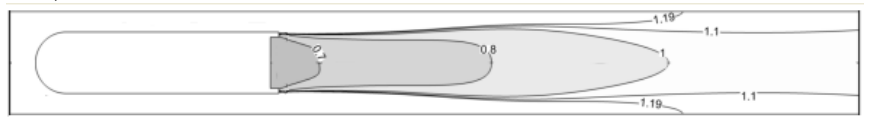

c)

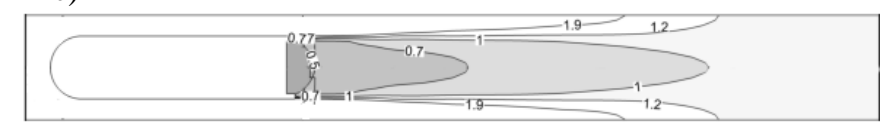

d)

Fig. 8. Contours of excess air ratio in the wake of a flat flame pylon when entering perpendicular to the gas jets in the entraining flow oxidizer at $K_{\mathrm{f}}=0.6$ : the diameter of the gas feed holes $\mathrm{d}=5 \mathrm{~mm}-\mathrm{a}, \mathrm{c} ; \mathrm{d}=10 \mathrm{~mm}-\mathrm{b}, \mathrm{d}$; in a plane gas supply inlet through the middle $-a, b$, in the plane passing between the gas supply inlet $-\mathrm{c}, \mathrm{d}$.
Analyzing the obtained results it is important to consider the fuel concentration in prefrontal niche, as known to be responsible for the formation of the stable reverse-flow area [11], [12]. Areas with a high content of fuel are presented with a darker color. So, for $K_{\mathrm{f}}=0.3$ (Fig. 7) all situations are in the flammable limit $(\alpha=0,5-1,9)$, while in the case with the stabilization zone diameter of $10 \mathrm{~mm}$ is characterized with the larger fuel supply in plane passing through the middle inlets compared to the situation for the geometry with $5 \mathrm{~mm}$ diameter inlets (see Fig. 6 a, b) similar pattern is present in a plane passing between the inlets (Fig. 7 c, d). Reducing the area of the air crossflow section twice (the case $K_{\mathrm{f}}=0.6$, Fig. 8) results in significant refueling of the reverse-flow area, especially in the case of gas supply with increased inlet diameter (Fig. $8 \mathrm{c}, \mathrm{d}$ ).

Thus, increasing the inlet diameter leads to the increase of the jet penetration depth into the air flow, thereby contributing to the diffusive combustion process increase in the system of flat flame stabilizers. It must be emphasized that the increase of flow blockage reduces the diffusion process (Fig. 8), while reducing the mixing flows length to combustible concentrations. As a whole, the analysis of the results shows that gas distribution of inlets larger than $5 \mathrm{~mm}$ requires clarification of earlier solutions for the geometric characteristics of the existing furnace burners.

\section{RECOMMENDATIONS FOR THE ROUND JETS FUEL DISTRIBUTION}

To determine the average regression dependence midcoefficient of excess air in the niche and the value of jets range under the jet and niche system the mathematical planning of the experiment is performed. The processing of the calculated data, have determined the coefficients of the regression equation for the average excess air ratio in niche cavity (see Fig. 9).

$$
\begin{aligned}
& \alpha=-0,143-0,344 \cdot d+0,11 \cdot d^{2}+0,473 \cdot L_{1}-7 \cdot 10^{-3} \cdot L_{1}^{2}- \\
& -0,231 \cdot q+5 \cdot 10^{-3} \cdot q^{2}-6 \cdot 10^{-2} \cdot d \cdot L_{1}+8 \cdot 10^{-4} \cdot d \cdot L_{1}^{2} .
\end{aligned}
$$

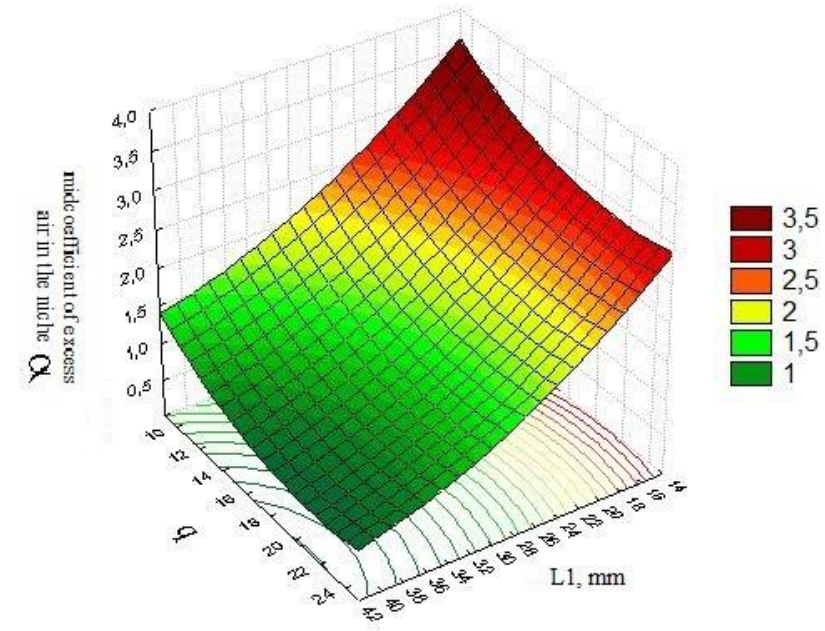

Fig. 9. The dependence of the excess air ratio in the flame stabilization area in the jet and niche system for $\mathrm{d}=10 \mathrm{~mm}$. 
The results of numerical studies also allow determining the coefficients in the regression equation for the jet range value under the jet and niching system (Fig. 10):

$$
\begin{aligned}
& h_{c}=-2,736+0,332 \cdot d+0,03 \cdot d^{2}+0,32 \cdot L_{1}-5,2 \cdot 10^{-3} \cdot L_{1}^{2}+ \\
& +0,52 \cdot q-13,3 \cdot 10^{-3} \cdot q^{2}-4 \cdot 10^{-2} \cdot d \cdot L_{1}+6,4 \cdot 10^{-4} \cdot d \cdot L_{1}^{2} .
\end{aligned}
$$

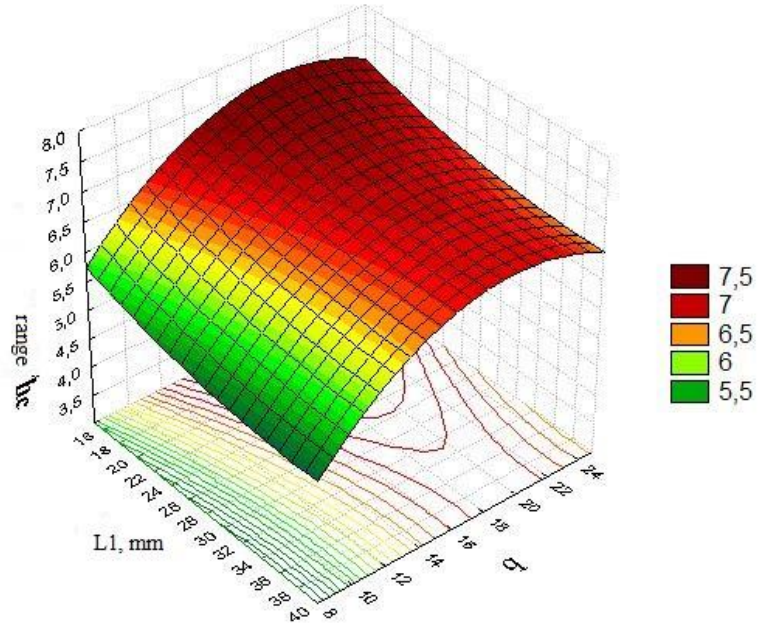

Fig. 10. The dependence of the gas jet range in the jet and niche system for $\mathrm{d}=10 \mathrm{~mm}$.

The prediction error in the given boundaries of the hydrodynamic characteristic values and number of jets distance from the niche leading edge does not exceed $9 \%$. Deviation of the results of velocity profiles mathematical modeling, concentrations and pressures from the experimental values for verification of $\mathrm{k}$-e turbulence model is average $12 \%$.

\section{ENGENEERING CHARASTERISTICS AND RESULTS OF BOILER DE-25 MODERNIZATION}

Oil-gas boilers of DE type of Biysk boiler plant and central boiler and turbine Institute are designed to generate saturated or slightly superheated steam with absolute pressure of $14 \mathrm{kgs} / \mathrm{cm}^{2}$ or $24 \mathrm{kgs} / \mathrm{cm}^{2}$, evaporation rate $25 \mathrm{t} / \mathrm{h}$ and gas and liquid fuels combustion The boiler has an inclined supporting frame that rests on the foundation. The mass of boiler and water elements, framework, tube-and-brick wall and encasing is transferred to a frame. Front bottom of the lower drum has a fixed support, and the remaining - sliding. The heat generator consists of upper and lower drums of equal length which are interconnected by a corridor spaced vertical curved tubes and will form respectively the first and second convective heating surface flues. Longitudinal pitch of boiling tubes along the drum is $90 \mathrm{~mm}$ and cross is $110 \mathrm{~mm}$ (Fig. 11).
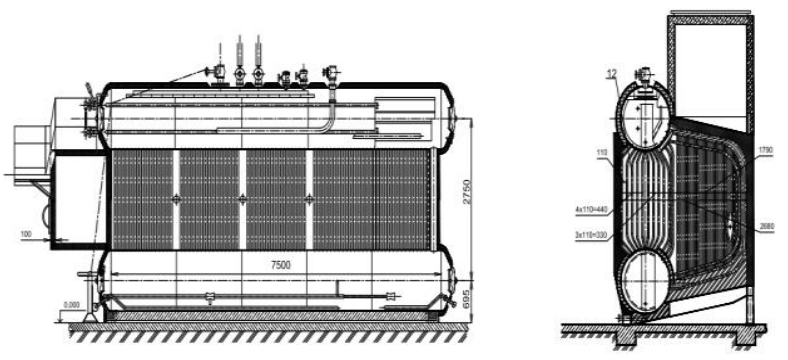

Fig. 11. Boiler DE-25-GMO
Each DE boiler is equipped according to the rules of Boiler Inspection:

- Two spring safety valves, one of which is a control; on boilers without superheaters both valves are set on the upper drum (and anyone can be selected as a control); on boilers with the superheater the control valve is on the superheater outlet header;

- Two water-level indicators;

- necessary number of thermometers, pressure gages, shutoff, drainage and drain valves;

- Regulation and safety instruments.

An existing burner has been replaced by furnace burner of the increased efficiency, reliability and ecological safety, on the basis of jet and niche technology of gas burning, taking into account recommendations for fuel dispensing by round jet with a diameter more than $5 \mathrm{~mm}$. Results of industrial tests showed high efficiency of the object in all researched range of operating modes (see Fig. 13). Measurements of the main operating characteristics were carried out in a load range $8-105 \%$ of nominal. Measurement scheme is given in Fig. 12.

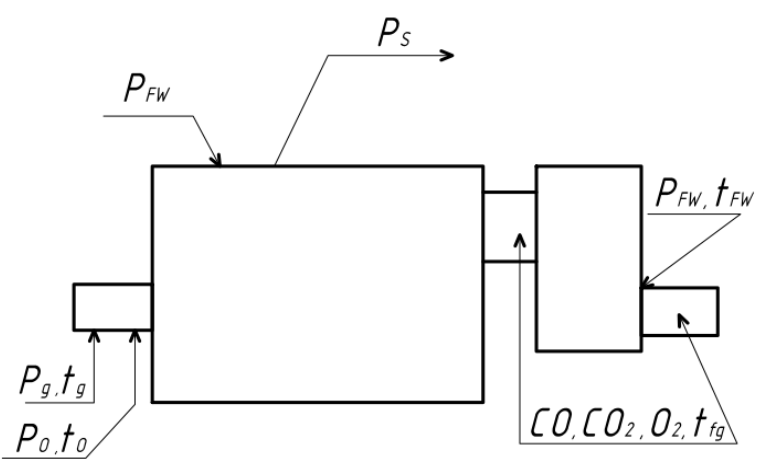

Fig. 12. Measurement with thermal boiler tests (indexes: "o"-oxidant; "g" - gases fuel; "FW" - feed water; "S" - steam; "fw" - flow gases).

$\Delta \mathrm{Gg}, \mathrm{m} 3 / \mathrm{t}$

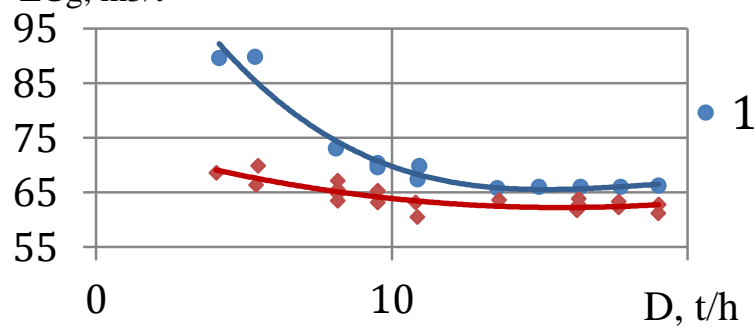

a)

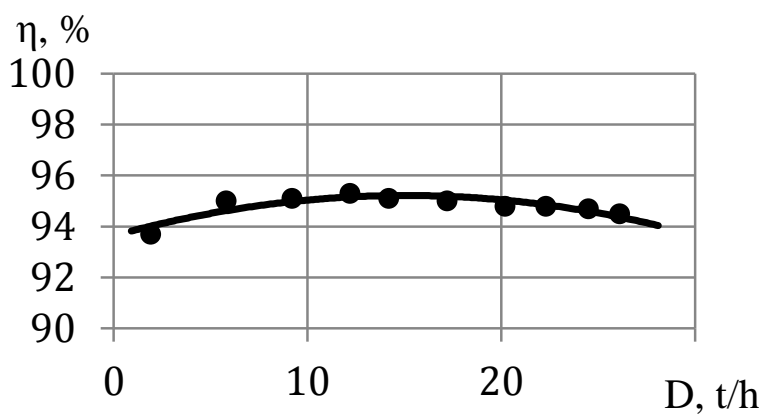

b) 


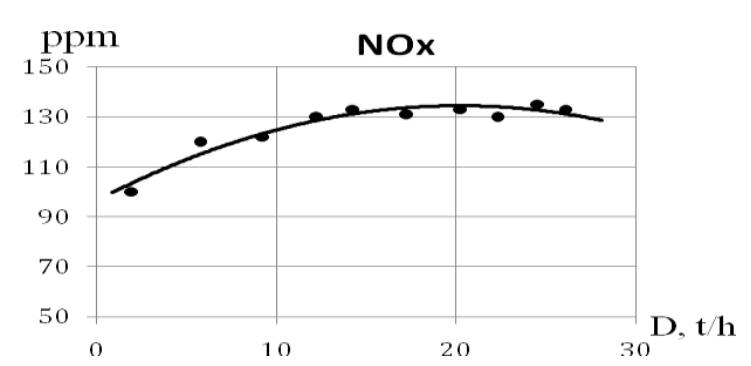

c)

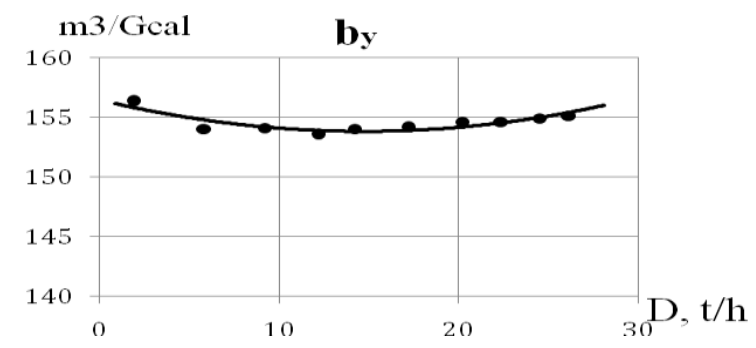

d)

Fig. 13. Results of industrial tests of a boiler: a - dependence of a fuel flow before modernization - 1 (furnace burner $Г М П)$, after modernization - 2 (jet and niche furnace burner - 45); b - dependence of boiler efficiency, c - emission values NOx, $\mathrm{d}$ - dependence of specific fuel consumption on evaporation output.

\section{CONCLUSION}

1. Analysis of results of hydrodynamics and mixing processes modeling, mass-exchanging characteristics and stabilization indexes calculation have shown the efficiency of gas distribution of a single-row jet system with increasing fuel flow section under specific recommendations.

2. Optimum ratios of geometrical and operating conditions of jet and niche furnace burner were determined by the method of mathematical planning of experiments.

3. Modernization of boiler DE-25 on the basis of jet and niche system allowed bringing object to a higher level of energy efficiency. Fuel saving is about $9 \%$ on a rated mode that reduced payback period for the modernization till to 6 months.

4. The object operates with high rates of efficiency in all researched load range. Satisfactory level on nitrogen oxide emissions has been achieved; levels of noise and vibrations have been reduced.

\section{REFERENCES}

[1] B. Raushenbah, S. Belyj, I. Bespalov. V. Borodachev, M. Volynskij, A. Prudnikov, Physical foundations of the working process in the combustion chambers of jet engines. Moscow, RU: Mechanical engineering, 1964, p. 525. (In Russian).

[2] C. E. Baukal, Industrial burners handbook. Tulsa, USA: CRS Press LLC, 2003, p. 808. http://dx.doi.org/10.1201/9780203488805

[3] M. Abdulin, "Development of new technologies of combustion taken to minimize fuel consumption and low emission of harmful emissions into the environment," in collective monograph "Municipal power system of Ukraine: state, problems and ways to modernization", 2007, vol. I, pp. 241-246. (In Russian).

[4] M. Z. Abdulin, G. R. Dvorcin, A. M. Zhuchenko, Ju. A. Kuleshov, I. Ovsienko, "Optimization of workflow is a way of improving the efficiency, environmental safety and reliability of the boilers." Heating news, pp. 31-34, 2008. (In Russian).

[5] M. Z. Abdulin, "Jet-niche technology of fuel combustion is a solution of the problems of modern burners." Construction market of Petersburg, pp. 55-57, 2008. (In Russian).

[6] A. Gourara, F. Roger, J. M. Most, H. Y. Wang, "Numerical and experimental investigation of the influence of wake Behind an injector Frame on jet dilution in a crossflow." Flow, Turbulence and Combustion, pp. 355-385, 2005. http://dx.doi.org/10.1007/s10494-005-1429-2

[7] M. Z. Abdulin, "Combustion technology is a basis for the creation of highly efficient combustion chambers." Aviation and space technology, pp. 40-42, 2009. (In Russian).

[8] D. G. Yang, J. Q. Li, Z. L. Fan, D. Yao, "Aerodynamic characteristics of transonic and supersonic flow over rectangular cavities." Flow, Turbulence and Combustion, vol. 84, no. 4, pp. 639-652, Jan. 2010. http://dx.doi.org/10.1007/s10494-010-9246-7

[9] N. M. Fialko, L. S. Butovskij, V. G. Prokopov, Ju. V. Sherenkovskij, N. O. Meranova, S. A. Aleshko, N. P. Polozenko, "Modeling of the flow structure of isothermal flow in layered lattice plane flame stabilizers." Industrial heat engineering, vol. 6, pp. 18-22, 2010. (In Russian).

[10] N. M. Fialko, L. S. Butovskij, V. G. Prokopov, E. A. Granovskaja, Ju. V. Sherenkovskij, S. A. Aleshko, P. S. Kohanenko, "Specifics of flow plane stabilizers by restricted flow." Industrial heat engineering, vol. 5, pp. 26-33, 2010. (In Russian).

[11] B. V. Perepelica, M. V. Shestakov, "Spatial structure of the flow at the expiration of a round jet in a narrow channel." Thermal physics and aeromechanic, vol. 16, pp. 57-60, 2009. (In Russian).

[12] Ju. M. Pchelkin, Combustors of turbine engines. Moscow, RU: Mechanical engineering, 1973, p. 392. (In Russian).

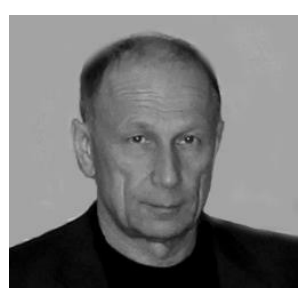

Michail Abdulin, associate professor of the department of cogeneration installations thermal and nuclear power plants faculty of heat and power engineering of NTUU «KPI». He received the degree of the candidate of science in 1986 in branch connected with methods of combustion gases fuel. Now his research interests include advance and implementation of jet-nishe technology in such objects of national energetic as: boilers, dryers, ovens etc. He is foundation of scientifically production association $\mathrm{H \Pi O}$ «CHT».

Address: Pobedy avenue 37, Kyiv, Ukraine

E-mail: mzabdulin@gmail.com

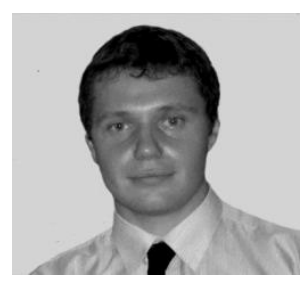

Alexander Siryi, assistant lecturer of the department of cogeneration installations thermal and nuclear power plants faculty of heat and power engineering of NTUU «KPI». He received his Bachelor and Master degree from the NTUU «KPI», in 2008, 2010. Currently PhD student. His research interests include methods of numerical simulation physical processes in industrial fire technical objects.

E-mail: Seruy_Alex@i.ua 